\title{
Differential Temporal Evolution Patterns in Brain Temperature in Different Ischemic Tissues in a Monkey Model of Middle Cerebral Artery Occlusion
}

\author{
Zhihua Sun, ${ }^{1}$ Jing Zhang, ${ }^{1}$ Yingmin Chen, ${ }^{2}$ Yunting Zhang, ${ }^{1}$ \\ Xuejun Zhang, ${ }^{1}$ Hong Guo, ${ }^{1}$ and Chunshui Yu ${ }^{1}$ \\ ${ }^{1}$ Department of Radiology, Tianjin Medical University General Hospital, No. 154, Anshan Dao Road, Heping District, \\ Tianjin 300052, China \\ ${ }^{2}$ Department of Radiology, The Second Hospital of Hebei Medical University, No. 215, Heping West Road, Hebei Province, \\ Shijiazhuang 050051, China
}

Correspondence should be addressed to Yunting Zhang, cjr.zhangyunting@vip.163.com

Received 19 July 2012; Accepted 31 August 2012

Academic Editor: Dobromir Dobrev

Copyright ( 2012 Zhihua Sun et al. This is an open access article distributed under the Creative Commons Attribution License, which permits unrestricted use, distribution, and reproduction in any medium, provided the original work is properly cited.

\begin{abstract}
Brain temperature is elevated in acute ischemic stroke, especially in the ischemic penumbra (IP). We attempted to investigate the dynamic evolution of brain temperature in different ischemic regions in a monkey model of middle cerebral artery occlusion. The brain temperature of different ischemic regions was measured with proton magnetic resonance spectroscopy $\left({ }^{1} \mathrm{H}\right.$ MRS), and the evolution processes of brain temperature were compared among different ischemic regions. We found that the normal (baseline) brain temperature of the monkey brain was $37.16^{\circ} \mathrm{C}$. In the artery occlusion stage, the mean brain temperature of ischemic tissue was $1.16^{\circ} \mathrm{C}$ higher than the baseline; however, this increase was region dependent, with $1.72^{\circ} \mathrm{C}$ in the IP, $1.08^{\circ} \mathrm{C}$ in the infarct core, and $0.62^{\circ} \mathrm{C}$ in the oligemic region. After recanalization, the brain temperature of the infarct core showed a pattern of an initial decrease accompanied by a subsequent increase. However, the brain temperature of the IP and oligemic region showed a monotonously and slowly decreased pattern. Our study suggests that in vivo measurement of brain temperature could help to identify whether ischemic tissue survives.
\end{abstract}

\section{Introduction}

An elevation in brain temperature is common in acute ischemic stroke and is associated with a worse outcome [1$3]$. One potential explanation is that pyrexia increases the brain temperature and the brain metabolic rate and could result in a more rapid exhaustion of limited energy and oxygen supplies and the increased production of free radicals and other toxic substances in ischemic tissue [4, 5]. For different blood flow and metabolic states, brain temperature could be different in different regions of ischemic tissue, that is, the infarct core, ischemic penumbra (IP), and the oligemic region.

Conventional methods of measuring brain temperature by invasive probes may monitor only one or a few locations simultaneously and cursorily, and they are difficult to be accepted clinically $[6,7]$. Several magnetic resonance parameters can be used for the noninvasive measurement of regional temperatures, including the diffusion coefficient, the longitudinal relaxation time constant (T1), and the proton resonance frequency (PRF), and the latter is more popular [8, 9]. Magnetic resonance (MR) spectroscopic techniques are, in principle, capable of estimating absolute temperatures. Therefore, it is possible to more accurately measure brain temperature in different regions of ischemic lesions, especially in the IP.

Many experimental and clinical studies have focused on brain temperature in the fields of cerebral infarction measured by magnetic resonance spectroscopy (MRS) $[6,10$, 11]. The brain temperature is elevated in the ischemic brain 
soon after stroke, prior to any increase in body temperature, and is significantly higher in probable penumbral tissue than in the infarct core or normal brain $[2,12]$. A previous study [13] found that there was a significant difference in brain temperature between ischemic tissue and the contralateral normal hemisphere in patients with middle cerebral artery occlusion. Additionally, the brain temperature of ischemic tissue could increase with the enlargement of lesion volume. However, there have been no reports on the detailed evolution of brain temperature in different regions of ischemic lesion at the early stage of onset.

In this work, we modified equations to measure brain temperature based on MRS PRF techniques in a physiological solution and used the final equation to calculate the brain temperature of different regions in ischemic lesion before and after reperfusion, especially the IP, in monkey middle cerebral artery occlusion (MCAO) models.

\section{Materials and Methods}

2.1. Animal Model. The experiment was approved by the Animal Care and Use Committee of Tianjin Medical University. Six mature male monkeys (Cynomolgus macaque) with a mean weight of $8.6 \mathrm{~kg}$ (range from 8 to $10 \mathrm{~kg}$ ) were supplied by Experimental Animal Center of Beijing Military Medical Academy.

All animals were fasted for 12-15 hours before the experiment. Anesthesia was induced by ketamine $(0.25 \mathrm{mg}$ intramuscular) and atropine $(8-10 \mathrm{mg} / \mathrm{kg}$ intramuscular) followed by $100 \mathrm{mg}$ ketamine and $50 \mathrm{mg}$ diazepam in a $500 \mathrm{~mL}$ NS intravenous drip. Physiological parameters, such as respiration, heart rate, body temperature, and blood pressure, were monitored.

The MCAO model was established through an autothrombus interventional method [14]. A one-inch incision was made in the right femoral groove, and the femoral artery and vein were isolated. The right femoral artery was punctured, and a 5 French catheter sheath was inserted. The 5 French catheter was introduced over a guide wire and navigated under fluoroscopy in a common carotid artery in close proximity to the internal carotid artery. A 1.7 French microcatheter (Prowler 10 with two markers, Cordis Corporation, $0.55 \mathrm{~mm}$ outside diameter) was introduced over a transcend microwire (Cordis). The microcatheter and the microguide wire were navigated into a selected branch of the middle cerebral artery (MCA) and advanced into a wedged position. The animals were maintained on a slow, continuous, heparinized drip infusion (100 U/hour) during the ischemia period. After one hour of ischemia, the microguide wire was removed, and the animal was analyzed with a magnetic resonance imaging (MRI) scanner. If cerebral ischemia was confirmed by diffusion-weighted imaging (DWI), the microcatheter was removed, and 250,000 units of urokinase in $50 \mathrm{~mL}$ normal saline (NS) was infused with a high-pressure injector $(2 \mathrm{~mL} / \mathrm{min})$. Effective reperfusion was confirmed by angiograms.

2.2. MRI and MRS Examination. MRI and MRS were performed with a GE $1.5 \mathrm{~T}$ Twin Speed Infinity with Excite
I magnetic resonance system $1 \mathrm{~h}$ after occlusion and $1 \mathrm{~h}$, $3 \mathrm{~h}, 6 \mathrm{~h}, 12 \mathrm{~h}$, and $24 \mathrm{~h}$ after recanalization. In addition, MRS was performed before occlusion to acquire normal brain temperature. We performed DWI, perfusion-weighted imaging (PWI), and $T_{2}$-weighted imaging $\left(T_{2} \mathrm{WI}\right)$ with a head coil. The $T_{2} \mathrm{WI}$ parameters were the following: repetition time $(\mathrm{TR})=4000 \mathrm{~ms}$; echo time $(\mathrm{TE})=106.4 \mathrm{~ms}$; averages $=2$; slice thickness $=2.5 \mathrm{~mm}$; gap $=0 \mathrm{~mm}$; field of view $($ FOV $)=18 \mathrm{~cm} \times 18 \mathrm{~cm}$; and matrix $=288 \times 256$. DWI was obtained using a single-shot spin-echo echo planar sequence with $\mathrm{TR}=6000 \mathrm{~ms} ; \mathrm{TE}=96.8 \mathrm{~ms}$; averages $=2 ; \mathrm{b}=$ $1000 \mathrm{~s} / \mathrm{mm}^{2} ; \mathrm{FOV}=18 \mathrm{~cm} \times 18 \mathrm{~cm}$; and matrix $=128 \times$ 128. PWI was obtained using a single-shot gradient-recalled echo planar imaging $T_{2}{ }^{*}$ WI sequence, that is, dynamic susceptibility contrast (DSC) MRI, with TR $=2000 \mathrm{~ms}$; $\mathrm{TE}=80 \mathrm{~ms} ;$ average $=1 ; \mathrm{FOV}=18 \mathrm{~cm} \times 18 \mathrm{~cm}$; and matrix $=128 \times 128$. A Gd-DTPA bolus $(0.1 \mathrm{mmol} / \mathrm{kg})$ was administered with a power injector at a rate of $2 \mathrm{~mL} / \mathrm{s}$, and $10 \mathrm{~mL}$ of isotonic saline was injected to wash the pipe. A total of 330 slices were acquired.

We used multivoxel point-resolved-spectroscopy(PRESS-) localized proton MRS with the voxel grid centered on the slice showing the maximum ischemic lesion on DWI. The imaging parameters were the following: $\mathrm{TR}=1500 \mathrm{~ms}$, $\mathrm{TE}=135 \mathrm{~ms}, \mathrm{FOV}=18 \mathrm{~cm} \times 18 \mathrm{~cm}$, matrix $=24 \times 24$, slice thickness $=10 \mathrm{~mm}$, and total acquired time $=9^{\prime} 6^{\prime \prime}$. The voxel grid $(1 \mathrm{~mL})$ was carefully placed within the brain to include as much of the visible ischemic lesion ipsilateral and contralateral normal brain as possible and to avoid contamination of the spectra with the lipid signal from bone marrow or subcutaneous fat. Almost thirty available voxel grids were obtained. We collected standard three-pulse chemical shift-selective (CHESS) water suppression and nonsuppression imaging. The spectroscopic data of water suppression were obtained with a 99\% suppression level.

2.3. Brain Temperature Calculation. Spectroscopic data were analyzed with the Java-based magnetic resonance user interface (jMRUI, http://www.mrui.uab.es/mrui/) package, spectroscopic time domain analysis software. Initially, the zeroorder phase correction of the water proton peak (effectively bringing water to a chemical shift of $4.70 \mathrm{ppm}$ ) was performed, and the residual water signal was then removed using the Hanckel-Lanczos Singular Value Decomposition (HLSVD) method. Spectroscopic data were Fourier transformed for display and visual quality control purposes using the Advanced Method for Accurate Robust and Efficient Spectral Fitting (AMARES) algorithm within the jMRUI package. Gaussian components were modeled in the time domain, including choline (Cho), creatine ( $\mathrm{Cr}$ ), N-acetyl aspartate-containing compounds (NAA), and lactate (Lac). The chemical shifts (i.e., frequency) of the fitted metabolite peaks were reported to a precision of $0.001 \mathrm{ppm}$ to confirm the chemical shifts of NAA. Spectra were automatically discarded if the fitted line widths were less than $1 \mathrm{~Hz}$ or greater than $10 \mathrm{~Hz}$. We inspected the spectroscopic data visually and discarded voxels laying on the edges of the PRESS excitation region, voxels containing cerebrospinal 
fluid (CSF) and those with poor quality, for example, having a badly elevated baseline or containing spurious peaks.

Temperature $T$ was derived from the chemical shift of water $\left(\mathrm{CS}_{\mathrm{H}_{2} \mathrm{O}}\right)$ using the following equation:

$$
T=T_{\text {ref }}+k\left(\mathrm{CS}_{\mathrm{H}_{2} \mathrm{O}}-\mathrm{CS}_{\mathrm{ref}}\right) .
$$

$\mathrm{CS}_{\text {ref }}$ is the (temperature-independent) chemical shift of a reference compound, $k$ is the coefficient of proportionality, and $T_{\text {ref }}$ is the reference temperature. Temperaturedependent changes in hydrogen bonding cause the water chemical shift to vary linearly with temperature at $0.01 \mathrm{ppm}$ per ${ }^{\circ} \mathrm{C}$. In our scanner, with $4.7 \mathrm{ppm}$ as the chemical shift of water and $37^{\circ} \mathrm{C}$ as the reference temperature, (1) was changed to the following:

$$
T=37+100\left(\mathrm{CS}_{\mathrm{NAA}}-\mathrm{CS}_{\mathrm{NAAref}}\right) .
$$

$\mathrm{CS}_{\text {NAA }}$ is the apparent chemical shift of NAA, and $\mathrm{CS}_{\text {NAAref }}$ is the reference chemical shift of NAA. We measured the temperature of a physiological solution (NAA $12.5 \mathrm{mMol}$, Cr $10.0 \mathrm{mMol}$ and Cho $3.0 \mathrm{mMol}$ ) with constant temperature equipment to acquire the $\mathrm{CS}_{\mathrm{NAAref}}$, which could be fit to the MR scan. There was a linear correlation between the $\mathrm{PRF}$ and the temperature of the solution ranging from $34^{\circ} \mathrm{C}$ to $44^{\circ} \mathrm{C}$, and the value of $\mathrm{CS}_{\text {NAAref }}$ was $2.039 \mathrm{ppm}$ by this method. Therefore, the following was used to calculate the brain temperature of each voxel grid in our study:

$$
T=37+100\left(\mathrm{CS}_{\mathrm{NAA}}-2.039\right) .
$$

2.4. Definition of Different Ischemic Regions. The mean transit time (MTT) map of PWI was processed by perfusion software using a GE Sun AW4.2 workstation, and the final infarct lesion was defined as abnormal signal intensity on $T_{2} \mathrm{WI}$ at $24 \mathrm{~h}$ of the reperfusion stage. We classified the ischemic lesion (abnormal signal intensity on MTT) into three types of tissue by DWI and MTT at the artery occlusion stage and $T_{2} \mathrm{WI}$ at $24 \mathrm{~h}$ of the reperfusion stage: the infarct core had high signal intensity on both DWI and $T_{2} \mathrm{WI}$, the IP had high signal intensity on DWI but normal on $T_{2} \mathrm{WI}$, and the oligemic region had normal signal intensity on both DWI and $T_{2} \mathrm{WI}$ but abnormal signal intensity on MTT (Figure 1). If one type of tissue was greater than $75 \%$ within one voxel grid of MRS, we named the voxel grid as this type of tissue. The brain temperature of each voxel grid and the mean and standard deviation of brain temperature for each tissue voxel category were calculated.

2.5. Statistical Analysis. Statistical analysis was performed with the SPSS 11.0 software package. Differences were considered statistically significant at $P<0.05$. The paired $t$ test was used to analyze the differences in brain temperature between normal bilateral hemispheres and between different ischemic regions and the contralateral brain. One-way ANOVA was performed between the brain temperature of three types of tissues.
TABLE 1: Normal brain temperature of monkeys.

\begin{tabular}{lcc}
\hline \multirow{2}{*}{ No. } & \multicolumn{2}{c}{ Temperature $\left({ }^{\circ} \mathrm{C}\right)$} \\
\hline 1 & Left hemisphere & Right hemisphere \\
2 & $37.05(0.26)$ & $37.07(0.27)$ \\
3 & $37.13(0.36)$ & $37.11(0.38)$ \\
4 & $37.26(0.26)$ & $37.28(0.23)$ \\
5 & $37.23(0.18)$ & $37.15(0.25)$ \\
6 & $37.16(0.28)$ & $37.24(0.21)$ \\
\hline Total & $37.16(0.21)$ & $37.17(0.24)$ \\
\hline
\end{tabular}

Note. Data are expressed by means (standard deviation).

\section{Results}

3.1. Normal Brain Temperature of the Monkey. The normal (baseline) brain temperature of the six monkeys was measured before the operation (Table 1). The mean baseline brain temperature was $37.16^{\circ} \mathrm{C}$ in left hemispheres, $37.17^{\circ} \mathrm{C}$ in right hemispheres, and $37.16^{\circ} \mathrm{C}$ in bilateral hemispheres. There was no significant difference in the baseline brain temperature between the bilateral hemispheres by paired $t$ test $(t=-1.659, P>0.05)$.

3.2. Evolution of Brain Temperature in Monkey MCAO and Reperfusion Models. MCAO models were successfully established in four out of the six monkeys, including one right and three left sides. Two monkeys were dead at 2 and 14 hours after reperfusion, respectively, probably because of large area of hemorrhagic infarction. And their data were not included in this study. Table 2 shows the brain temperature of different ischemic tissues and the contralateral hemisphere at the artery occlusion stage $(0 \mathrm{~h})$ and different time points of the reperfusion stage. At the artery occlusion stage, the mean brain temperature of ischemic tissue was $1.16 \pm 0.15^{\circ} \mathrm{C}$ higher than the baseline brain temperature. The increase in brain temperature was region dependent, with $1.72 \pm$ $0.08^{\circ} \mathrm{C}$ in the IP, $1.08 \pm 0.19^{\circ} \mathrm{C}$ in the infarct core, and $0.62 \pm 0.14^{\circ} \mathrm{C}$ in the oligemic region compared to the basal brain temperature. In the reperfusion stage, the evolution of brain temperature differed in the infarct core, IP and oligemic region (Figure 2). After recanalization, the brain temperature of the infarct core showed a pattern of an initial decrease accompanied by a subsequent increase. However, the brain temperature of the IP and oligemic region showed a monotonously and slowly decreased pattern. The brain temperature of the contralateral hemisphere increased slightly $\left(0.23^{\circ} \mathrm{C}\right)$ compared to the baseline brain temperature.

Table 3 shows the differences in brain temperature between different ischemic tissues and the contralateral hemisphere. There were significant differences in brain temperature between the infarct core and contralateral hemisphere at $0 \mathrm{~h}, 1 \mathrm{~h}, 12 \mathrm{~h}$, and $24 \mathrm{~h}$, between the IP and contralateral hemisphere within $6 \mathrm{~h}$, and between the oligemic region and the contralateral hemisphere within $3 \mathrm{~h}(P<$ 0.05 ), while no significant differences were found between the infarct core and contralateral hemisphere at $3 \mathrm{~h}$ and $6 \mathrm{~h}$, 


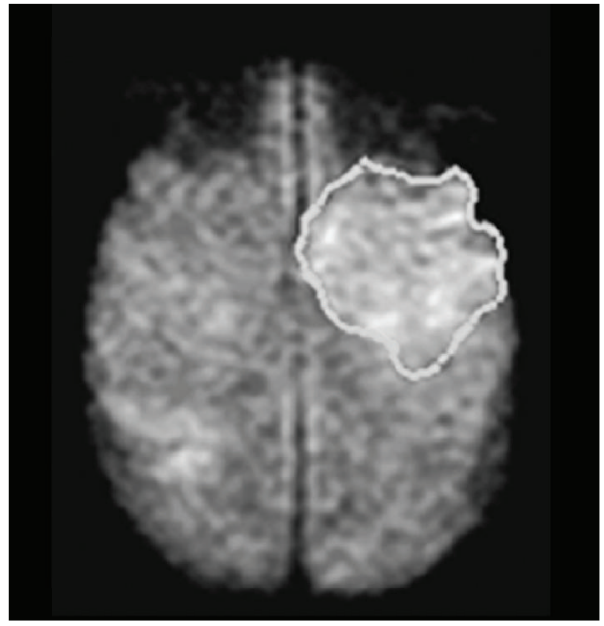

(a)

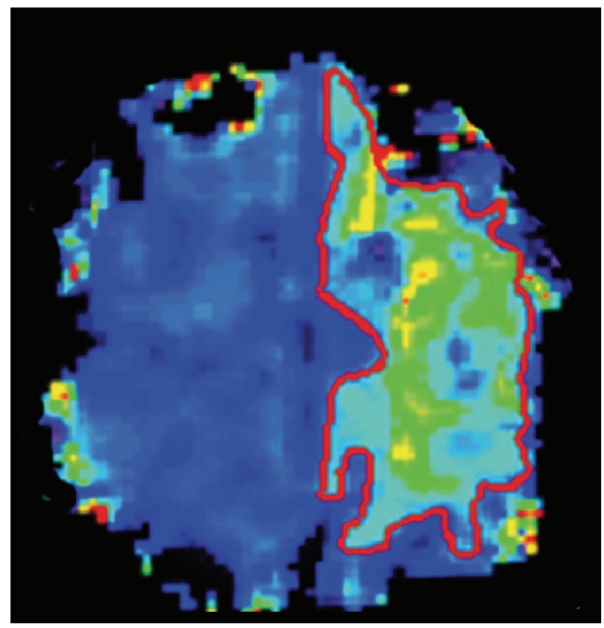

(c)

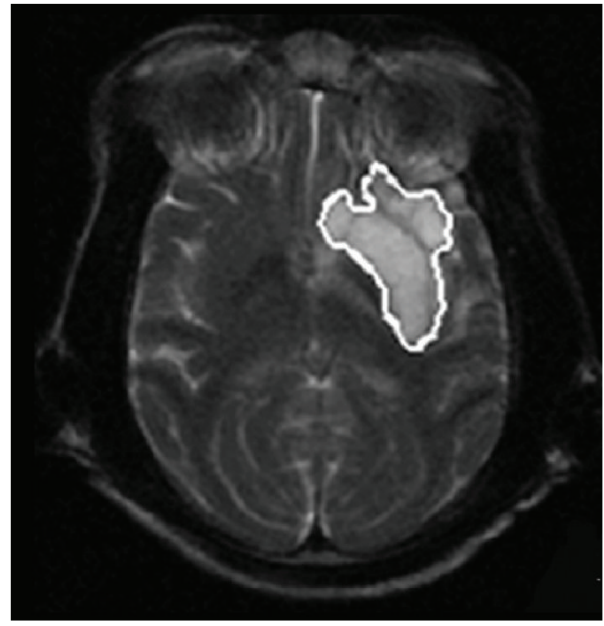

(b)

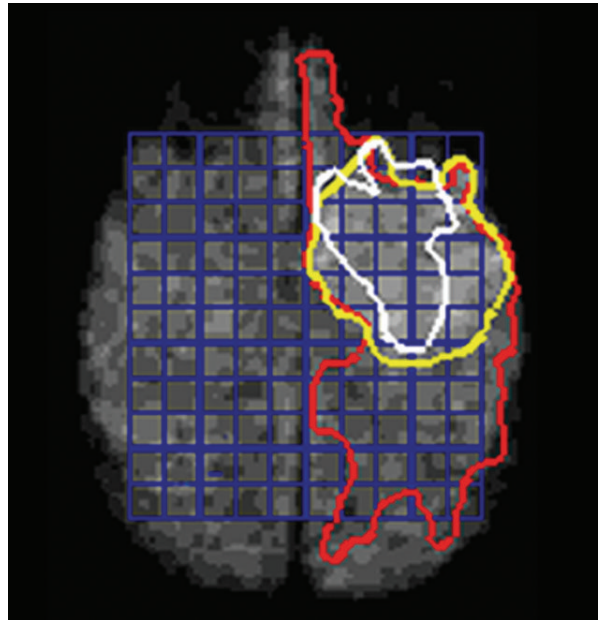

(d)

Figure 1: Definition of different ischemic regions. DWI (a) and MTT (c) at the artery occlusion stage and $T_{2}$ WI (b) at $24 \mathrm{~h}$ are used to define the infarct core, IP, and oligemic region. On the localized DWI of MRS (d), overlapped imaging shows the infarcted core (white), IP (yellow), and oligemia (red).

TABLE 2: The brain temperature of different ischemic tissues and contralateral hemisphere at artery occlusion stage $(0 \mathrm{~h})$ and different time points of reperfusion stage in monkey MCAO model.

\begin{tabular}{lcccc}
\hline Time after modeling (hours) & Infarct core & IP & $\begin{array}{c}\text { Temperature }\left({ }^{\circ} \mathrm{C}\right) \\
\text { Oligemia region }\end{array}$ & Contralateral hemisphere \\
\hline 0 & $38.26(0.27)$ & $38.90(0.19)$ & $37.80(0.14)$ & $37.46(0.14)$ \\
1 & $37.81(0.26)$ & $38.34(0.38)$ & $37.92(0.34)$ & $37.37(0.46)$ \\
3 & $37.21(0.36)$ & $38.29(0.23)$ & $37.79(0.33)$ & $37.41(0.37)$ \\
6 & $37.26(0.29)$ & $38.22(0.25)$ & $37.59(0.35)$ & $37.31(0.32)$ \\
12 & $38.48(0.17)$ & $37.56(0.28)$ & $37.49(0.38)$ & $37.33(0.39)$ \\
24 & $38.63(0.19)$ & $37.47(0.35)$ & $37.29(0.35)$ & $37.28(0.45)$ \\
\hline
\end{tabular}

Note. Data are expressed by means (standard deviation).

between the IP and contralateral hemisphere at $12 \mathrm{~h}$ and $24 \mathrm{~h}$, or between the oligemic region and contralateral hemisphere at and after $6 \mathrm{~h}(P>0.05)$.

3.3. Differences in Brain Temperature among Different Ischemic Regions. One-way ANOVA was performed on the brain temperature of different ischemic tissues at different time points (Table 4). There were significant differences in the brain temperature among different ischemic tissues at each time point ( $F$ values were $27.64,8.32,26.46,21.55,27.64$, and 47.90 at 0 h, 1 h, 3 h, 6 h, 12 h, and 24 h, resp., $P<0.05$ ). Bonferroni's method was used for post hoc comparisons. 
TABle 3: Paired $t$-test of brain temperature between different ischemic tissues and contralateral hemisphere in monkey MCAO model ( $t$ value).

\begin{tabular}{lccc}
\hline Time $(\mathrm{h})$ & Infarct core and contralateral hemisphere & IP and contralateral hemisphere & Oligemia region and contralateral hemisphere \\
\hline 0 & $5.383^{*}$ & $9.69^{*}$ & $2.788^{*}$ \\
1 & $2.961^{*}$ & $6.527^{*}$ & $3.028^{*}$ \\
3 & -1.346 & $5.922^{*}$ & $2.557^{*}$ \\
6 & -0.336 & $6.124^{*}$ & 1.884 \\
12 & $7.739^{*}$ & 1.548 & 1.077 \\
24 & 9.085 & 1.279 & 0.067 \\
\hline
\end{tabular}

Note. ${ }^{*}$ represents $P<0.05$.

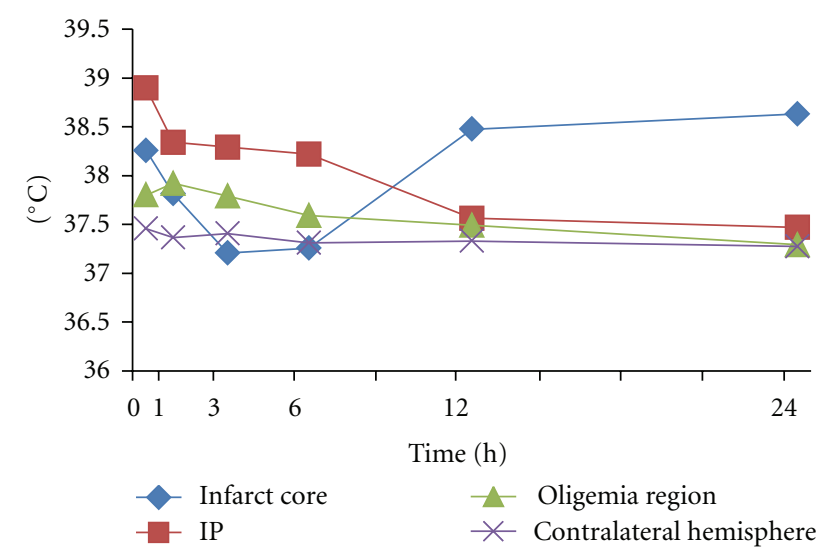

FIGURE 2: Evolution of the brain temperature of different ischemic regions and the contralateral hemisphere at the artery occlusion stage $(0 \mathrm{~h})$ and reperfusion stage in the monkey MCAO model.

There were significant differences in brain temperature between the infarct core and IP at each time point, between the IP and oligemic region within $6 \mathrm{~h}$, and between the infarct core and oligemic region at $0 \mathrm{~h}, 3 \mathrm{~h}, 12 \mathrm{~h}$, and $24 \mathrm{~h}$ $(P<0.05)$, while there were no significant differences between the IP and oligemic region at $12 \mathrm{~h}$ and $24 \mathrm{~h}$ or between the infarct core and oligemic region at $1 \mathrm{~h}$ and $6 \mathrm{~h}$ $(P>0.05)$.

\section{Discussion}

Previous studies of brain temperature were limited by the reliance on invasive measurement techniques, such as probes inserted in brain tissue [15-17]. In this situation, the brain temperature could be lower than the actual temperature if the brain surface was exposed to cooler environmental air. Invasive techniques may inevitably induce local microlesions and inflammatory responses adjacent to probes, which might affect brain temperature. Infrared thermometry is a noninvasive method, but it fails to measure the deep brain temperature due to the limited depth penetration and cannot make an accurate localization because of the limited spatial resolution of this method. MRS is a validated method for noninvasively measuring brain temperature using the principle that the water frequency shift relative to $\mathrm{N}$-acetyl aspartate is temperature dependent $[8,10,18]$.
Moreover, MRS thermometry could avoid most of the abovementioned weaknesses of other methods.

Because equations for calculating brain temperature (especially $\mathrm{CS}_{\text {NAAref }}$ ) are dependent on the MR scanner and sequence parameters, the temperature equation can be modified based on in vivo models or healthy volunteers [18]. In our study, we used a physiological solution within a constant temperature to acquire the $\mathrm{CS}_{\text {NAAref }}$. Therefore, the $\mathrm{CS}_{\text {NAAref }}$ was more accurate to calculate the brain temperature.

There are also several limitations regarding MRS thermometry. The signal intensity from NAA as a chemical shift reference should be high enough for calculating the temperature. However, NAA decreases gradually after a stroke; as a consequence, studies of the temperature of ischemic brain tissue by MRS should be limited in acute stoke [18]. Another limitation is the environmental temperature of the MR scanner. In most scanners, the temperature should be $18-20^{\circ} \mathrm{C}$ perennially. The brain temperature would be lower after a long-term examination. A previous study [12] found that there was a statistically significant reduction in temperature of $0.09^{\circ} \mathrm{C}$ per scan $(P=0.0001)$ across four sequential MRS scans on 4 normal volunteers, presumably due to cooling by the air current in the bore of the magnet (or relative cerebral inactivity during the scan). In our study, the MR examination was arranged as DWI, $T_{2} \mathrm{WI}$, PWI, and MRS for $15 \mathrm{~min}$ for all of the time points, which can at least partly reduce the effect of environmental temperature on the longitudinal changes of brain temperature.

The perfusion state is critical for the temperature of the brain tissue; for example, reduced blood flow could impair heat exchange and result in a higher temperature in ischemic tissue [2]. According to the perfusion state theory, the brain temperature in the infarct core should increase the most because it has the lowest blood flow. However, we found that the highest increase in brain temperature was in the IP, followed by the infarct core and the oligemic region at the artery occlusion stage in the monkey MCAO model. This finding suggests that the perfusion state was not the only factor for brain temperature elevation in ischemic tissue, and other factors might play a role.

The brain tissue temperature is mainly determined by two processes, heat production and heat radiation. In the infarct core, reduced blood flow induces the reduction of heat radiation and increased anaerobic metabolism induces the increase in heat production, which may both result in the 
TABLE 4: ANOVA among brain temperature of different ischemic tissues and contralateral hemisphere in monkey MCAO model ( $P$ value).

\begin{tabular}{lccc}
\hline Time $(\mathrm{h})$ & Infarct core and IP & IP and oligemia region & Infarct core and oligemia region \\
\hline 0 & $0.032^{*}$ & $0.007^{*}$ & $0.005^{*}$ \\
1 & $0.004^{*}$ & $0.005^{*}$ & 0.287 \\
3 & $0.003^{*}$ & $0.013^{*}$ & $0.011^{*}$ \\
6 & $0.001^{*}$ & $0.011^{*}$ & 0.346 \\
12 & $0.001^{*}$ & 0.078 & $0.035^{*}$ \\
24 & $0.001^{*}$ & 0.135 & $0.024^{*}$ \\
\hline
\end{tabular}

Note. * represents $P<0.05$.
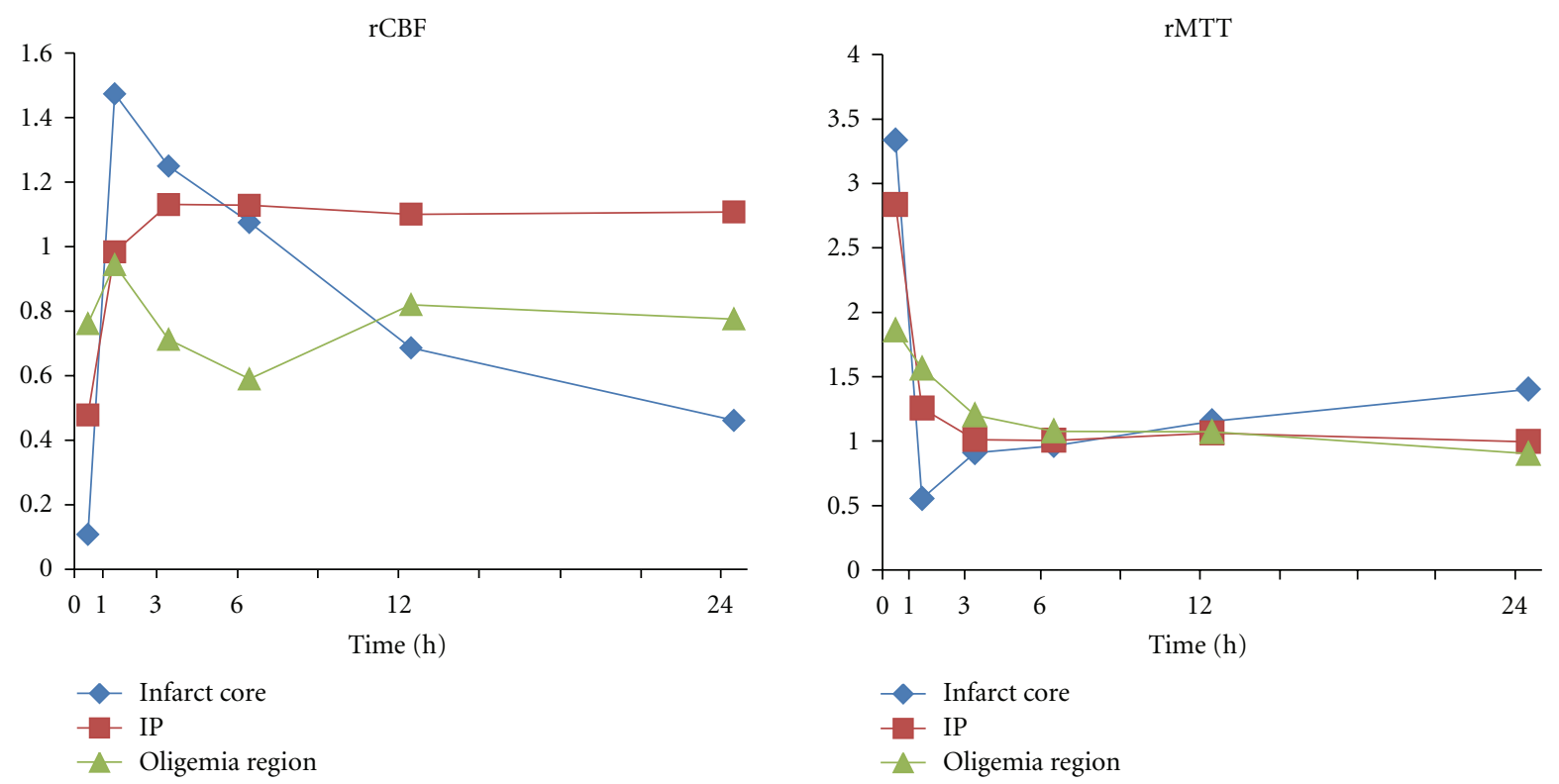

FIGURE 3: Evolution of rCBF and rMTT in different ischemic regions at the artery occlusion stage $(0 \mathrm{~h})$ and reperfusion stage in the monkey MCAO model.

elevated brain temperature. In IP tissue, reduced blood flow may induce the reduction of heat radiation, while an increase in heat production is induced by the subsequent events, including both aerobic and anaerobic metabolism [19-22], inflammation and the release of excitatory amino acids [23, 24]. These complex processes may account for the higher elevated brain temperature in the IP than in the infarct core or oligemic regions at the artery occlusion stage. In addition, uncoupling protein 2 (UCP-2) is a natural neuroprotective factor in the human ischemic brain [25-28]. UCP-2 upregulation may regulate ATP synthesis by uncoupling oxidation from phosphorylation, thus dissipating energy as local heat, and may simultaneously be responsible for the early rise in lesion brain temperature after stroke.

After recanalization, the brain temperature of the ischemic tissue was decreased with time, which can be mainly explained by the changes of the perfusion states in these brain regions (Figure 3 ). In the infarct core, a temporary and rapid increase in $\mathrm{rCBF}$ and shortening of the rMTT, that is, overperfusion, result in the clearance of accumulated heat, which can account for the sharply decreased brain temperature. However, after $6 \mathrm{~h}$, both decreased $\mathrm{rCBF}$ and delayed MTT lead to the reincrease in the temperature. In particular, at
$12 \mathrm{~h}$ after recanalization, the brain temperature of the infarct core was even higher than the IP and oligemic region and was accompanied by the lowest $\mathrm{rCBF}$ and highest rMTT in the infarct core. However, the brain temperature of the IP and oligemic region recovered to normal levels as in the contralateral hemisphere without repeated elevation, suggesting that the cells in these regions were viable or salvaged.

The brain temperature in the contralateral hemisphere (which may be more closely related to body temperature) is slightly elevated after a stroke, reflecting increased neuronal activity in response to the ischemia [2]. Therefore, in our study, the brain temperature in the ischemic region was evaluated by comparison with the baseline brain temperature, which is more reasonable than the previously used method that regarded the brain temperature of the contralateral hemisphere as a control state.

In the present study, we focused on detailed changes in the brain temperature of different ischemic tissues before and after reperfusion by ${ }^{1} \mathrm{H}$ MRS. We found that the IP and infarct core showed different evolution patterns of brain temperature, which may provide us with a method to discriminate the IP from the infarct core. However, our study also had some limitations. The first limitation is that 
the classification of different ischemic tissues in our study was based on DWI and PWI at the artery occlusion stage and $T_{2} \mathrm{WI}$ at $24 \mathrm{~h}$ of the reperfusion stage. IP was defined as low-perfusion tissue with high signal intensity on DWI but normal intensity on $T_{2} \mathrm{WI}$, but this definition may miss part of the IP tissue peripheral to the abnormal DWI regions [29-31]. The second limitation is the relatively small sample size of our study. The last limitation is that we do not know whether the results obtained from the monkey MCAO model can be generalized to human stroke patients. Further studies are needed to overcome the above limitations and to clarify the mechanism underlying the evolution of the brain temperature of ischemic tissue.

\section{Conclusion}

After ischemic stroke, the infarct core and IP have different evolution patterns of brain temperature, which suggests that in vivo measurement of brain temperature could help to identify whether ischemic tissue survives.

\section{Acknowledgment}

This work was supported by Tianjin Municipal Nature Science Foundation (no. 09JCYBJC11500 and 12JCZDJC23800), National Basic Research Program of China (973 Program, 2010CB732506), National Natural Science Foundation of China (NSFC, no. 30730036), and Doctorial Foundation of Ministry of Education of China (no. 20091202110006).

\section{References}

[1] J. Castillo, A. Dávalos, J. Marrugat, and M. Noya, “Timing for fever-related brain damage in acute ischemic stroke," Stroke, vol. 29, no. 12, pp. 2455-2460, 1998.

[2] B. Karaszewski, J. M. Wardlaw, I. Marshall et al., "Measurement of brain temperature with magnetic resonance spectroscopy in acute ischemic stroke," Annals of Neurology, vol. 60, no. 4, pp. 438-446, 2006.

[3] J. Zaremba, "Hyperthermia in ischemic stroke," Medical Science Monitor, vol. 10, no. 6, pp. RA148-RA153, 2004.

[4] R. N. Ichord, F. J. Northington, D. Van Wylen, M. V. Johnston, C. Kwon, and R. J. Traystman, "Brain $\mathrm{O}_{2}$ consumption and glutamate release during hypoglycémie coma in piglets are temperature sensitive," American Journal of Physiology, vol. 276, no. 6, part 2, pp. H2053-H2062, 1999.

[5] S. Asai, H. Zhao, T. Kohno, Y. Takahashi, T. Nagata, and K. Ishikawa, "Quantitative evaluation of extracellular glutamate concentration in postischemic glutamate re-uptake, dependent on brain temperature, in the rat following severe global brain ischemia," Brain Research, vol. 864, no. 1, pp. 60-68, 2000.

[6] S. Schwab, M. Spranger, A. Aschoff, T. Steiner, and W. Hacke, "Brain temperature monitoring and modulation in patients with severe MCA infarction," Neurology, vol. 48, no. 3, pp. 762-767, 1997.

[7] J. J. Legos, A. A. Mangoni, S. J. Read et al., "Programmable microchip monitoring of post-stroke pyrexia: effects of aspirin and paracetamol on temperature and infarct size in the rat," Journal of Neuroscience Methods, vol. 113, no. 2, pp. 159-166, 2002.
[8] E. B. Cady, J. Penrice, and N. J. Robertson, "Improved reproducibility of MRS regional brain thermometry by 'amplitudeweighted combination," NMR in Biomedicine, vol. 24, no. 7, pp. 865-872, 2011.

[9] R. Jayasundar and V. P. Singh, "In vivo temperature measurements in brain tumors using proton MR spectroscopy," Neurology India, vol. 50, no. 4, pp. 436-439, 2002.

[10] E. B. Cady, P. C. D’Souza, J. Penrice, and A. Lorek, "The estimation of local brain temperature by in vivo ${ }^{1} \mathrm{H}$ magnetic resonance spectroscopy," Magnetic Resonance in Medicine, vol. 33, no. 6, pp. 862-867, 1995.

[11] R. J. T. Corbett, P. D. Purdy, A. R. Laptook, C. Chaney, and D. Garcia, "Noninvasive measurement of brain temperature after stroke," American Journal of Neuroradiology, vol. 20, no. 10, pp. 1851-1857, 1999.

[12] B. Karaszewski, J. M. Wardlaw, I. Marshall et al., "Early brain temperature elevation and anaerobic metabolism in human acute ischaemic stroke," Brain, vol. 132, no. 4, pp. 955-964, 2009.

[13] K. R. Thulborn, T. S. Gindin, D. Davis, and P. Erb, "Comprehensive MR imaging protocol for stroke management: tissue sodium concentration as a measure of tissue viability in nonhuman primate studies and in clinical studies," Radiology, vol. 213, no. 1, pp. 156-166, 1999.

[14] J. Zhang, Y. M. Chen, and Y. T. Zhang, "Blood-oxygenationlevel-dependent-(BOLD-) based R2' MRI study in monkey model of reversible middle cerebral artery occlusion," Journal of Biomedicine and Biotechnology, vol. 2011, Article ID 318346, 8 pages, 2011.

[15] J. C. LaManna, K. A. McCracken, M. Patil, and O. Prohaska, "Brain tissue temperature: activation-induced changes determined with a new multisensor probe," Advances in Experimental Medicine and Biology, vol. 222, pp. 383-389, 1988.

[16] E. M. Nemoto, C. Jungreis, D. Larnard, H. Kuwabara, M. Horowitz, and A. Kassam, "Hyperthermia and hypermetabolism in focal cerebral ischemia," Advances in Experimental Medicine and Biology, vol. 566, pp. 83-89, 2005.

[17] H. K. F. Trübel, P. K. Maciejewski, J. H. Farber, and F. Hyder, "Brain temperature measured by ${ }^{1} \mathrm{H}-\mathrm{NMR}$ in conjunction with a lanthanide complex," Journal of Applied Physiology, vol. 94, no. 4, pp. 1641-1649, 2003.

[18] I. Marshall, B. Karaszewski, J. M. Wardlaw et al., "Measurement of regional brain temperature using proton spectroscopic imaging: validation and application to acute ischemic stroke," Magnetic Resonance Imaging, vol. 24, no. 6, pp. 699706, 2006.

[19] S. M. Maniega, V. Cvoro, P. A. Armitage, I. Marshall, M. E. Bastin, and J. M. Wardlaw, "Choline and creatine are not reliable denominators for calculating metabolite ratios in acute ischemic stroke," Stroke, vol. 39, no. 9, pp. 2467-2469, 2008.

[20] K. Kuroda, R. V. Mulkern, K. Oshio et al., "Temperature mapping using the water proton chemical shift: selfreferenced method with echo-planar spectroscopic imaging," Magnetic Resonance in Medicine, vol. 43, no. 2, pp. 220-225, 2000.

[21] K. Kuroda, N. Takei, R. V. Mulkern et al., "Feasibility of internally referenced brain temperature imaging with a metabolite signal," Magnetic Resonance in Medical Sciences, vol. 2, no. 1, pp. 17-22, 2003.

[22] A. Schurr, "Lactate, glucose and energy metabolism in the ischemic brain," International Journal of Molecular Medicine, vol. 10, no. 2, pp. 131-136, 2002.

[23] A. R. Parry-Jones, T. Liimatainen, R. A. Kauppinen, O. H. J. Gröhn, and N. J. Rothwell, "Interleukin-1 exacerbates focal cerebral ischemia and reduces ischemic brain temperature in 
the rat," Magnetic Resonance in Medicine, vol. 59, no. 6, pp. 1239-1249, 2008.

[24] M. A. Yenari and H. S. Han, "Influence of hypothermia on post-ischemic inflammation: role of nuclear factor kappa B (NFkB)," Neurochemistry International, vol. 49, no. 2, pp. 164169, 2006.

[25] T. Nakase, Y. Yoshida, and K. Nagata, "Amplified expression of uncoupling proteins in human brain ischemic lesions," Neuropathology, vol. 27, no. 5, pp. 442-447, 2007.

[26] G. Mattiasson, M. Shamloo, G. Gido et al., "Uncoupling protein-2 prevents neuronal death and diminishes brain dysfunction after stroke and brain trauma," Nature Medicine, vol. 9, no. 8, pp. 1062-1068, 2003.

[27] J. S. Kim-Han and L. L. Dugan, "Mitochondrial uncoupling proteins in the central nervous system," Antioxidants \& Redox Signaling, vol. 7, no. 9-10, pp. 1173-1181, 2005.

[28] T. L. Horvath, S. Diano, and C. Barnstable, "Mitochondrial uncoupling protein 2 in the central nervous system: neuromodulator and neuroprotector," Biochemical Pharmacology, vol. 65, no. 12, pp. 1917-1921, 2003.

[29] C. S. Kidwell, J. R. Alger, and J. L. Saver, "Evolving paradigms in neuroimaging of the ischemic penumbra," Stroke, vol. 35, no. 11, pp. 2662-2665, 2004.

[30] Z. H. Sun, X. J. Zhang, Y. T. Zhang, H. Guo, J. Zhang, and C. Yu, "Estimation of the ischemic penumbra based on CT perfusion: a pilot study," Academic Radiology, vol. 17, no. 12, pp. 1535-1542, 2010.

[31] C. S. Rivers, J. M. Wardlaw, P. A. Armitage et al., "Do acute diffusion- and perfusion-weighted MRI lesions identify final infarct volume in ischemic stroke?" Stroke, vol. 37, no. 1, pp. 98-104, 2006. 


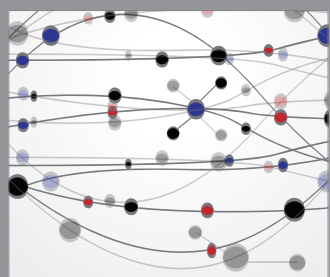

The Scientific World Journal
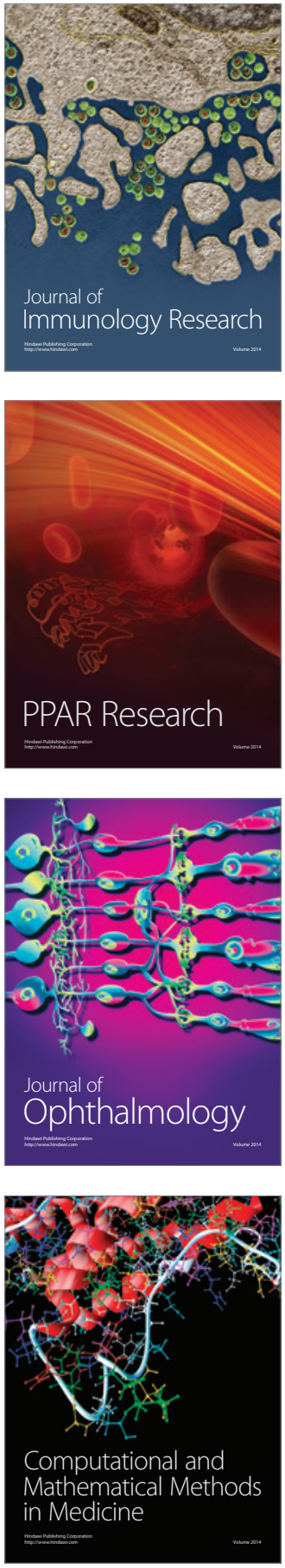

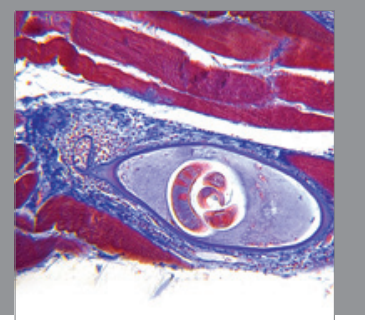

Gastroenterology

Research and Practice
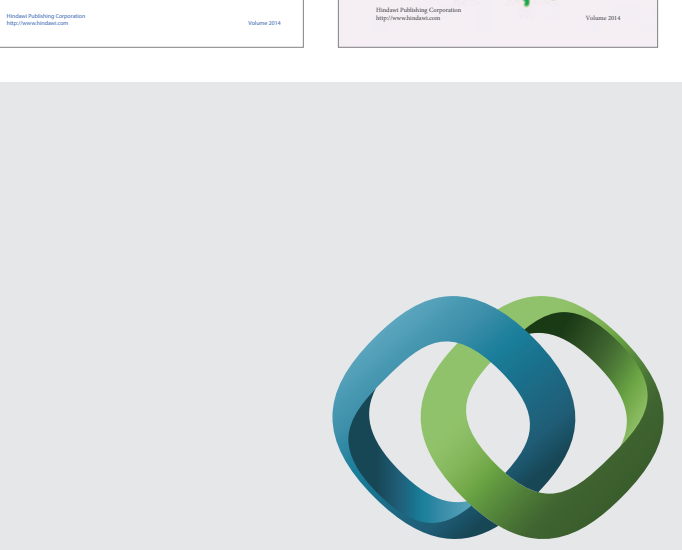

\section{Hindawi}

Submit your manuscripts at

http://www.hindawi.com
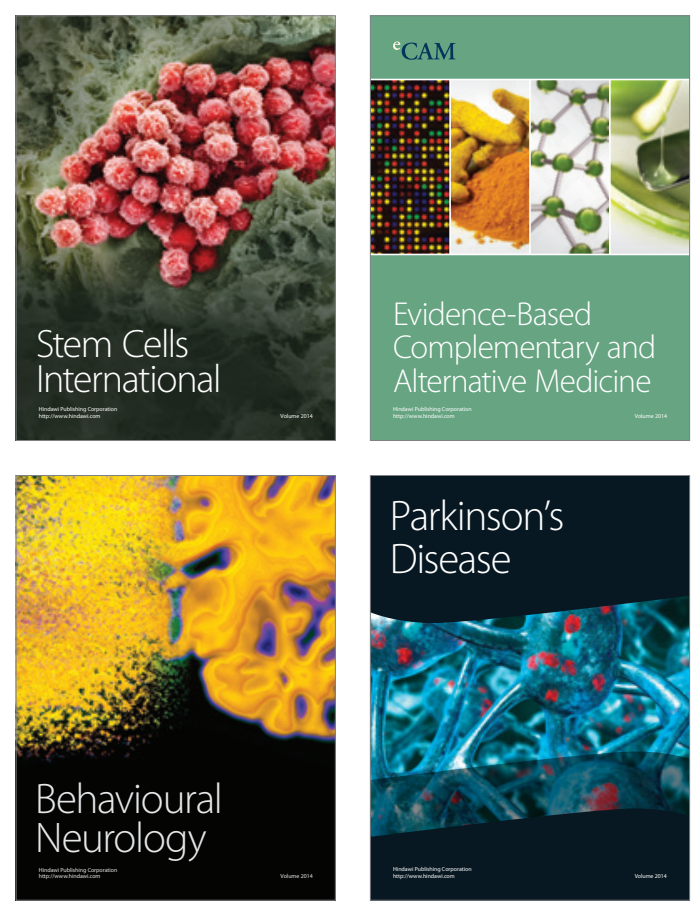

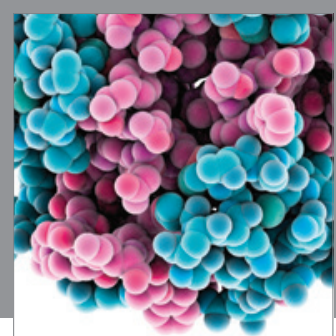

Journal of
Diabetes Research

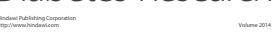

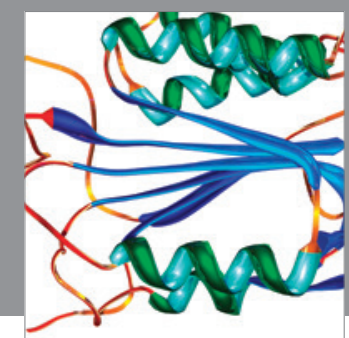

Disease Markers
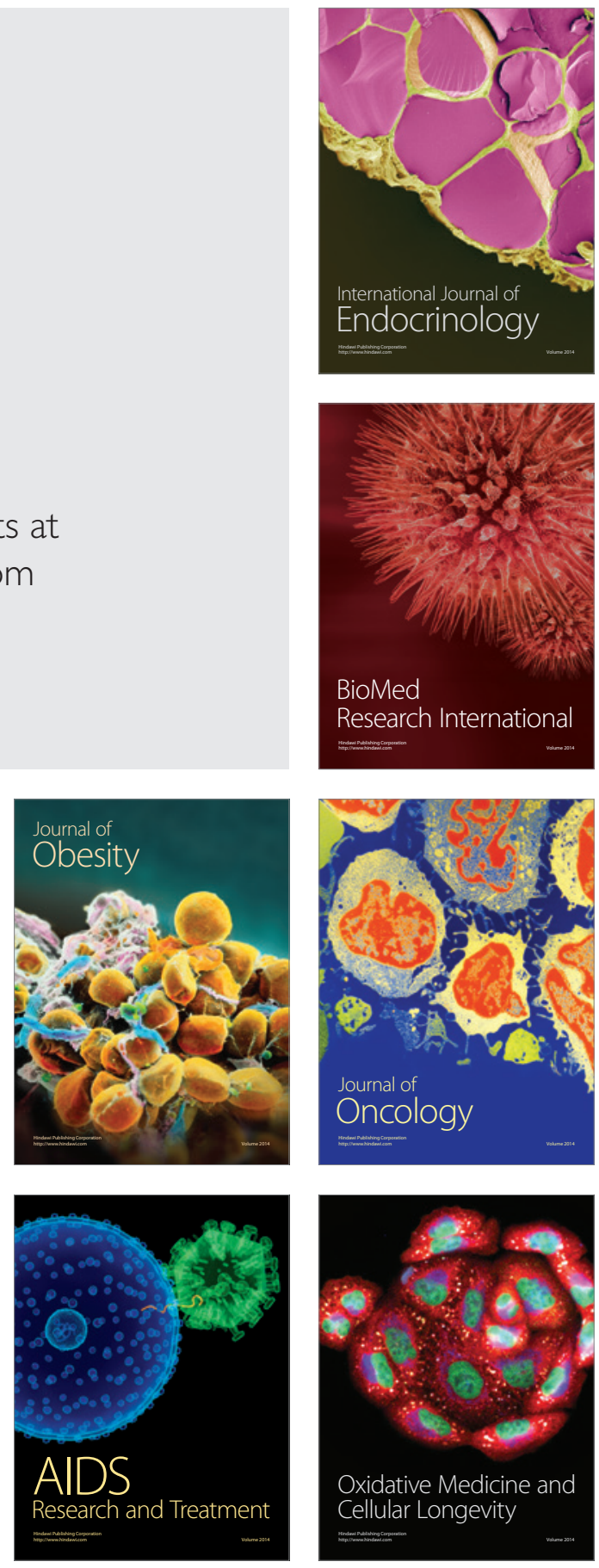